\title{
Antioxidant effect of a polyphenol-rich grape pomace extract on motility, viability and lipid peroxidation of thawed bovine spermatozoa
}

\author{
Vasiliki G Sapanidou', loannis Margaritis ${ }^{1}$, Nektarios Siahos ${ }^{1}$, Konstantinos Arsenopoulos', Eleni Dragatidou',
} Ioannis A Taitzoglou', Ioannis A Zervos ${ }^{1}$, Alexandros Theodoridis ${ }^{2}$ and Maria P Tsantarliotou ${ }^{1 *}$

\begin{abstract}
Background: Grape extracts of the Greek species Vitis vinifera possess potent antioxidant properties in vitro. The freeze/thaw process and the preparation of semen during assisted reproductive techniques can adversely affect the functional integrity of spermatozoa. The objective was to assess the effect of three different concentrations $\left(1 \mu \mathrm{g} \mathrm{ml}^{-1}, 2 \mu \mathrm{g} \mathrm{ml}^{-1}\right.$ and $\left.5 \mathrm{\mu g} \mathrm{ml}^{-1}\right)$ of a polyphenol-rich grape pomace extract on motility, viability, acrosomal and lipid peroxidation status of thawed bovine spermatozoa after 2 and 4 hrs of incubation.

Results: The results indicate that the percentage of "Rapid" spermatozoa remained significantly increased $(p<0.05)$ in the presence of $5 \mathrm{\mu g} \mathrm{ml}^{-1}$ of the extract, compared to the control after 2 hrs of incubation. Additionally, the incubation of spermatozoa with $2 \mathrm{\mu g} \mathrm{ml}^{-1}$ and $5 \mathrm{\mu g} \mathrm{ml}^{-1}$ of the extract for 2 hrs resulted in a significantly better maintenance of viable spermatozoa with intact acrosome $(p<0.05)$. The other parameters did not show statistically significant changes. Moreover, the presence of $2 \mu \mathrm{g} \mathrm{ml}^{-1}$ and $5 \mu \mathrm{g} \mathrm{ml} \mathrm{m}^{-1}$ of the extract kept the levels of Malondialdehyde (MDA) production in significantly lower level, compared to the other groups, after 2 hrs and 4 hrs of incubation $(p<0.05)$. Particularly, a dose-dependent effect was noticed after 2 hrs of incubation.
\end{abstract}

Conclusions: Our results suggest that the grape pomace extract exerts a powerful antioxidant role, by suppressing lipid peroxidation, and provides protection in terms of motility and acrosomal integrity, which are correlated with in vivo fertility. The optimal extract concentration is $5 \mu \mathrm{g} \mathrm{ml}^{-1}$.

Keywords: Motility, Viability, Lipid peroxidation, Spermatozoa, Grape, Polyphenols

\section{Background}

Motility is an essential property of fertile spermatozoa in order to traverse the female reproductive tract, reach the site of fertilization and penetrate the zona pellucida of the oocyte [1]. The most efficient method to estimate fertility is to accomplish in vitro fertilization, which is time consuming and expensive [2]. Besides, other groups suggest that simple laboratory techniques such as motility assessment, DNA fragmentation index and evaluation of plasma membrane integrity would be more advantageous [3]. Computer Assisted Sperm Analysis (CASA) is a nonsubjective analyzer which provides the opportunity to

\footnotetext{
* Correspondence: mtsant@vet.auth.gr

'Laboratory of Physiology, School of Veterinary Medicine, Faculty of Health Science, Aristotle University of Thessaloniki, 54124 Thessaloniki, Greece Full list of author information is available at the end of the article
}

assess multiple characteristics with repeatability. It is noteworthy that the total number of motile spermatozoa tended to be higher in high fertility bulls [4] while the evaluation of kinematic parameters obtained by CASA are highly correlated with higher in vivo fertility [5]. Moreover, successful fertilization predisposes that all the membranes of spermatozoon are intact [4], otherwise, fertilization would be compromised. For this reason, the membrane status is an indicator of sperm competency.

Motile and fertile spermatozoa during their aerobic metabolism produce physiological amounts of reactive oxygen species (ROS) [6]. Low levels of ROS are essential for hyperactivation motility, capacitation/acrosome reaction and other physiological processes [7]. However, spermatozoa are particularly susceptible to oxidative injury due to the abundance of plasma membrane 
polyunsaturated fatty acids [8]. These unsaturated fatty acids provide fluidity that is necessary for membrane fusion events (e.g., the acrosome reaction and sperm-egg interaction) and for sperm motility. However, the unsaturated nature of these molecules predisposes them to free radical attack and ongoing lipid peroxidation (LPO) throughout the sperm plasma membrane. This phenomenon has deleterious effects on the fluidity, integrity and flexibility of sperm plasma membrane, characteristics associated with fertilizing capacity. Once this process has been initiated, accumulation of lipid peroxides occurs on the sperm surface (resulting in loss of sperm motility) and oxidative damage to DNA can ensue [9]. LPO is known to be an informative and diagnostic tool to evaluate the membrane integrity [10].

Thawed mammalian spermatozoa do not contain sufficient mechanisms to counteract ROS because the seminal plasma, which is enriched with antioxidant compounds, is removed during the preparation of sperm for in vitro fertilization [11]. Cryopreservation is associated with ROS production, which leads to lipid peroxidation, resulting in loss of motility and membrane integrity [12]. On this basis, several in vitro studies have shown a positive effect of antioxidant supplementation on sperm characterisrics. Among the antioxidants employed in vitro, various plant-derived ones have been used after thawing, such as crocin from Crocus sativus L. [13,14].

Grape extracts are considered as potent antioxidants and free radical scavengers, as shown in several studies [15]. The antioxidant properties of the polyphenolic compounds that grapes possess are responsible for the recently growing interest in the biological importance of grape extracts [16]. Polyphenols are secondary metabolites of plants, which are divided in two main categories, namely flavonoids and nonflavonoids. They exert a powerful role in absorption and neutralization of ROS [17]. Among the most common polyphenols found in grape extracts are trans-resveratrol, catechin, epicatechin, quercetin and gallic acid [18]. During the last decade, research has demonstrated that several grape extracts of the grape species Vitis vinifera possess potent antioxidant properties in vitro, as they scavenge several free radicals, such as 1,1-diphenyl-2-picrylhydrazyl (DPPH $\left.{ }^{*}\right), 2,2$-Azino-bis-(3-ethylbenzthiazoline-sulphonic acid $\left(\mathrm{ABTS}^{\bullet+}\right)$, superoxide $\left(\mathrm{O}_{2}^{*-}\right)$, hydroxyl $\left(\mathrm{OH}^{*}\right)$, and peroxyl (ROO') radicals [19]. Thus, the aim of the present study was to examine whether a polyphenol-rich grape pomace extract would have any effect on several motility parameters, estimated by CASA, on viability, acrosomal status and lipid peroxidaton level of thawed bovine spermatozoa in the media of Assisted Reproductive Techniques (ART) settings.

\section{Results \\ Motility}

The results are presented in Table 1, which includes semen features regarding motility. The percentage of "rapid" spermatozoa remained increased after incubation with $5 \mu \mathrm{g} \mathrm{ml}{ }^{-1}$ of the grape extract compared to the control group at 2 hrs of incubation $(p=0.017)$. The "medium" and "slow" movement did not show any statistically significant differences (data not shown). Progressive motility and the velocity parameters VCL, VSL, VAP, as well as ALH (for abbreviations, see Methods) did not show any statistically significant differences in each time point $(p>0.05)$.

Table 1 The effect of different doses of the grape extract on CASA parameters (mean \pm SD)

\begin{tabular}{|c|c|c|c|c|c|c|c|c|}
\hline $\begin{array}{l}\text { Time } \\
\text { (hrs) }\end{array}$ & $\begin{array}{l}\text { Conc. of grape extract } \\
\qquad\left(\mu \mathrm{g} \mathrm{ml}^{-1}\right)\end{array}$ & $\begin{array}{c}\text { Total motile } \\
\text { (\%) }\end{array}$ & $\begin{array}{c}\text { Rapid } \\
(\%)\end{array}$ & $\begin{array}{c}\text { Progressive motile } \\
\text { (\%) }\end{array}$ & $\begin{array}{c}\text { VSL } \\
\left(\mu \mathrm{mec}^{-1}\right)\end{array}$ & $\begin{array}{c}\text { VCL } \\
\left(\mu \mathrm{mec}^{-1}\right)\end{array}$ & $\begin{array}{c}\text { VAP } \\
\left(\mu \mathrm{mec}^{-1}\right)\end{array}$ & $\begin{array}{l}\text { ALH } \\
(\mu \mathrm{m})\end{array}$ \\
\hline \multirow[t]{4}{*}{0} & 0 & $69.17 \pm 5.16$ & $50.50 \pm 5.15$ & $17.85 \pm 4.53$ & $21.25 \pm 4.89$ & $57.93 \pm 2.97$ & $31.28 \pm 5.62$ & $2.35 \pm 0.30$ \\
\hline & 1 & $77.97 \pm 5.38$ & $51.70 \pm 6.27$ & $20.10 \pm 5.74$ & $20.53 \pm 4.32$ & $63.0 \pm 8.28$ & $36.13 \pm 3.97$ & $2.88 \pm 0.39$ \\
\hline & 2 & $79.6 \pm 5.36$ & $56.20 \pm 1.50$ & $21.15 \pm 4.84$ & $23.73 \pm 7.79$ & $63.8 \pm 3.84$ & $37.53 \pm 2.87$ & $3.28 \pm 0.57$ \\
\hline & 5 & $81.07 \pm 3.7$ & $56.25 \pm 2.21$ & $23.52 \pm 1.64$ & $25.15 \pm 11.27$ & $64.65 \pm 2.3$ & $43.88 \pm 6.8$ & $2.78 \pm 0.15$ \\
\hline \multirow[t]{4}{*}{2} & 0 & $45.65 \pm 17.61$ & $19.02 \pm 6.22^{a}$ & $14.70 \pm 3.98$ & $29.8 \pm 16.37$ & $54.48 \pm 14.06$ & $38.25 \pm 13.84$ & $3.08 \pm 0.31$ \\
\hline & 1 & $64.47 \pm 16.03$ & $31.57 \pm 10.16^{a b}$ & $22.57 \pm 8.14$ & $24.0 \pm 8.89$ & $57.85 \pm 3.88$ & $39.0 \pm 5.10$ & $2.78 \pm 0.15$ \\
\hline & 2 & $63.82 \pm 9.53$ & $38.57 \pm 5.57^{\mathrm{ab}}$ & $22.32 \pm 7.48$ & $33.15 \pm 12.03$ & $63.10 \pm 14.66$ & $42.25 \pm 14.42$ & $3.2 \pm 0.16$ \\
\hline & 5 & $71.85 \pm 3.61$ & $44.15 \pm 11.60^{b}$ & $26.07 \pm 3.06$ & $28.48 \pm 16.06$ & $63.83 \pm 8.23$ & $39.88 \pm 5.67$ & $3.12 \pm 0.46$ \\
\hline \multirow[t]{4}{*}{4} & 0 & $36.23 \pm 6.97$ & $13.00 \pm 3.94$ & $12.57 \pm 2.00$ & $19.48 \pm 6.91$ & $47.68 \pm 8.14$ & $28.38 \pm 4.07$ & $2.52 \pm 0.58$ \\
\hline & 1 & $40.05 \pm 13.04$ & $16.47 \pm 7.78$ & $10.22 \pm 4.77$ & $24.45 \pm 9.82$ & $45.53 \pm 9.73$ & $25.88 \pm 4.51$ & $2.50 \pm 0.58$ \\
\hline & 2 & $38.7 \pm 4.86$ & $15.78 \pm 5.57$ & $12.30 \pm 3.56$ & $19.48 \pm 8.38$ & $44.93 \pm 9.35$ & $25.18 \pm 6.19$ & $2.10 \pm 0.84$ \\
\hline & 5 & $51.40 \pm 6.22$ & $25.52 \pm 7.59$ & $15.97 \pm 3.25$ & $19.78 \pm 10.45$ & $51.93 \pm 10.54$ & $28.70 \pm 4.25$ & $2.85 \pm 0.70$ \\
\hline
\end{tabular}

a,b Different letters in each treatment indicate statistically significant differences within each given time point $(p<0.05, \mathrm{n}=4)$. 


\section{Viability}

Table 2 summarizes the results from the evaluation of the viability and the acrosomal status of spermatozoa, treated with different concentrations of grape extract (1 $\mu \mathrm{g} \mathrm{ml} \mathrm{m}^{-1}, 2 \mu \mathrm{g} \mathrm{ml} \mathrm{m}^{-1}, 5 \mu \mathrm{g} \mathrm{ml} \mathrm{m}^{-1}$ ), in the presence of a negative control. Data showed that the incubation of spermatozoa with $2 \mu \mathrm{g} \mathrm{ml}^{-1}$ and $5 \mu \mathrm{g} \mathrm{ml} \mathrm{m}^{-1}$ of the grape extract for 2 hrs kept sperm viability higher compared to the other groups $(p<0.05)$. Furthermore, the coincubation of spermatozoa with $5 \mu \mathrm{g} \mathrm{ml}^{-1}$ of the grape extract maintained almost the same percentage of alive spermatozoa with intact acrosome after $4 \mathrm{hrs}$ of incubation. These data indicate that there is no effect on the acrosomal integrity of the spermatozoa due to the presence of the grape extract. Finally, neither other grape extract concentration nor incubation time affected viability and acrosomal status of the samples evaluated.

\section{Measurement of lipid peroxidation}

Figure 1 summarizes the results of the TBARS assay. Corresponding to supplementation, all the groups treated with the grape pomace extract had lower MDA production compared to the control, significantly or not. During 2 hrs of incubation, a dose-dependent reduction in MDA levels was observed. Moreover, statistically significant differences were noticed between: i) control and $2 \mu \mathrm{g} \mathrm{ml}{ }^{-1}$ $(p=0.002)$, ii) control and $5 \mu \mathrm{g} \mathrm{ml}^{-1}(p<0.001)$, iii) $1 \mu \mathrm{g} \mathrm{ml}^{-1}$ and $5 \mu \mathrm{g} \mathrm{m}{ }^{-1}(p=0.001)$ and iv) $5 \mu \mathrm{g} \mathrm{ml}{ }^{-1}$ and all groups $(p<0.03)$. After 4 hrs of incubation, the maximum antioxidant effect was observed in the presence of $2 \mu \mathrm{g} \mathrm{ml} l^{-1}$ compared to all the other groups, while $5 \mu \mathrm{g} \mathrm{ml}{ }^{-1}$ decreased the production of MDA significantly, compared to the control group $(p<0.05)$. Nevertheless,

Table 2 The effect of different doses of the grape extract on sperm viability (mean \pm SD)

\begin{tabular}{|c|c|c|}
\hline Time (hours) & Extract $\left(\mu \mathrm{g} \mathrm{ml}^{-1}\right)$ & $\begin{array}{c}\text { Alive spermatozoa-intact } \\
\text { acrosome }(\%)\end{array}$ \\
\hline \multirow[t]{4}{*}{0} & 0 & $81.0 \pm 2.4$ \\
\hline & 1 & $77.0 \pm 3.0$ \\
\hline & 2 & $82.0 \pm 1.8$ \\
\hline & 5 & $79.0 \pm 3.2$ \\
\hline \multirow[t]{4}{*}{2} & 0 & $49.0 \pm 2.5^{a}$ \\
\hline & 1 & $48.0 \pm 1.8^{\mathrm{a}}$ \\
\hline & 2 & $54.5 \pm 1.5^{b}$ \\
\hline & 5 & $55.6 \pm 1.5^{b}$ \\
\hline \multirow[t]{4}{*}{4} & 0 & $39.5 \pm 2.9$ \\
\hline & 1 & $39.0 \pm 5.4$ \\
\hline & 2 & $37.3 \pm 2.6$ \\
\hline & 5 & $47.4 \pm 13.5$ \\
\hline
\end{tabular}

Different letters in each column indicate statistically significant difference between the treatments within each given time point $(p<0.05, n=4)$.

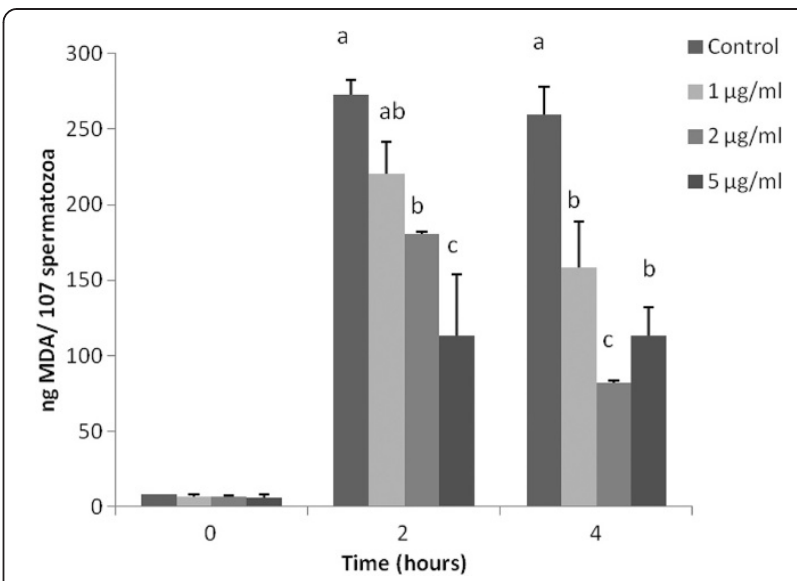

Figure 1 The effect of the grape extract on LPO production of sperm (mean $\pm \mathbf{S D}$ ). Different letters indicate statistically significant differences between different concentrations within each time point $(p<0.05)$.

no statistically significant difference was observed between $2 \mu \mathrm{g} \mathrm{ml}^{-1}$ and $5 \mu \mathrm{g} \mathrm{ml}{ }^{-1}$ after 4 hrs of incubation $(p>0.05)$.

\section{Discussion}

In the present study, the co-incubation of thawed bovine sperm with $5 \mu \mathrm{g} \mathrm{ml}^{-1}$ of the polyphenol-rich grape pomace extract, maintained the percentage of rapid spermatozoa compared to the control after $2 \mathrm{hrs}$ of sperm incubation. In our experiment we did not notice any influence of the grape extract on CASA kinematic parameters like VCL, VSL, VAP and ALH. The addition of $5 \mu \mathrm{g} \mathrm{m}{ }^{-1}$ of the polyphenol-rich grape pomace extract protected spermatozoa from lipid peroxidation after 2 hrs of incubation more effectively compared to all the other groups. LPO can cause protein oxidation which leads to loss of motility [20,21]. The detection of high levels of MDA is negatively correlated with the motility parameters and the ability of the spermatozoa to penetrate the zona pellucida [22]. In conclusion, as for motility, the beneficial effect of the polyphenol-rich grape pomace extract at the concentration of $5 \mu \mathrm{g} \mathrm{ml}{ }^{-1}$ may be due to the protective properties it exerts against LPO.

Regarding viability, the incubation of sperm supplemented with $2 \mu \mathrm{g} \mathrm{ml}^{-1}$ or $5 \mu \mathrm{g} \mathrm{ml} \mathrm{m}^{-1}$ of the extract, resulted in a significantly better maintenance of viable spermatozoa at $2 \mathrm{hrs}$ of incubation, compared to all other groups, without showing any negative effect on acrosomal integrity. Several authors reported that fertility is positively correlated to plasma membrane integrity and progressive motility [3,23].

However, there is evidence that the presence of some antioxidants (e.g. ascorbic acid and vitamine E) correlates beneficially with sperm characteristics such as motility, viability and lower production of MDA levels [24-26]. 
Polyphenols exert a significant antioxidant role due to their oxidoreduction properties. For this reason, they are capable of reducing lipid peroxidation in sperm [27]. The grape pomace extract used in the present study has a total polyphenol content equal to $648 \mathrm{mg}$ of gallic acid per $g$ of extract [28]. In our experiment, the incubation of spermatozoa with $2 \mu \mathrm{g} \mathrm{ml}^{-1}$ and $5 \mu \mathrm{g} \mathrm{ml}^{-1}$ resulted in an effective protection of the membrane's phopsholipids after 2 hrs of incubation, while the former concentration suppressed the levels of MDA after 4 hrs of incubation. Furthermore, it has been reported that polyphenols increase cell viability, decrease intracellular $\mathrm{Ca}^{2+}$ levels and ROS formation and improve mitochondrial membrane potential in cells [29]. More specifically, quercetin and resveratrol affect intracellular calcium release, which can be observed through enhanced or sustained motility during storage or incubation without loss of sperm function. Nevertheless, the addition of resveratrol or quercetin before cryopreservation did not significantly affect progressive motility and plasma or membrane integrity of ovine spermatozoa [30]. In general, the action of phenolic compounds depends on their structure, dose, and method of administration as well as the half-life of the radical to be intercepted [31]. Our data indicate that the grape pomace extract used, inhibited the peroxidative damage in sperm and showed a dose-dependent reduction in MDA production after 2 hrs of incubation when different concentrations added to sperm samples. Finally, despite the fact that $2 \mu \mathrm{g}$ $\mathrm{ml}^{-1}$ resulted in a significantly lower reduction of LPO after $4 \mathrm{hrs}$, spermatozoa that were treated with this concentration failed to maintain not only the total and progressive motility, but also the viability and acrosomal integrity. It is suggested that mild and low oxidative stress may enhance the fertilizing potential by promoting hyperactivation motility and capacitation, through increased tyrosine phosphorylation [32]. On the other hand, it should be noted that mild LPO predisposes the cell to capacitation/acrosome reaction and that extensive LPO is significantly correlated with impaired embryo development [33].

\section{Conclusion}

In conclusion, the polyphenol-rich grape pomace extract used in our study provided protection to thawed spermatozoa against oxidative damage by suppressing lipid peroxidation and consequently maintained essential sperm characteristics, such as motility, viability and acrosomal integrity. In our experiments we showed that the optimal extract concentration that is capable of maintaining the functional integrity of spermatozoa is $5 \mu \mathrm{g} \mathrm{ml}^{-1}$. Further research should be held to investigate these effects on pre-freezing sperm as well as during the freezing-thawing process.

\section{Methods}

Samples from frozen-thawed spermatozoa of four different mature bulls of proven fertility were used in this experiment. The samples were kindly offered by the Center of Artificial Insemination of Thessaloniki (Nea Ionia, Greece). The same four bulls were used in all replicates. Straws were thawed $\left(37^{\circ} \mathrm{C}\right.$ for $\left.40 \mathrm{sec}\right)$ and their contents were pooled in a conical tube. The samples were washed with $3 \times$ volume of Sperm Talp (100 mM $\mathrm{NaCl}, 3.1 \mathrm{mM} \mathrm{KCl}, 25 \mathrm{mM} \mathrm{NaHCO}, 0.29 \mathrm{mM}$ $\mathrm{NaH}_{2} \mathrm{PO}_{4}, 21.6 \mathrm{mM}$ Na Lactate, $2 \mathrm{mM} \mathrm{CaCl}, 1.5 \mathrm{mM}$ $\mathrm{MgCl}_{2}, 10 \mathrm{mM}$ Hepes supplemented with $0.6 \%$ bovine serum, $1 \mathrm{mM}$ sodium pyruvate and $50 \mu \mathrm{g} \mathrm{ml}^{-1}$ gentamycin) and centrifuged at $1000 \mathrm{rpm}$ for $10 \mathrm{~min}$. The procedure was repeated twice. Sperm concentration was determined with a haemocytometer (Optik Labor, Grale HDS, New South Wales, Australia).

The washed pool of spermatozoa was divided in four tubes and Sperm Talp was added in order to achieve a concentration of $20 \times 10^{6}$ cells ml $^{-1}$ in each tube. A tube was served as control, while the others were supplemented with four different concentrations of a polyphenol-rich grape pomace extract $\left(1 \mu \mathrm{g} \mathrm{ml}^{-1}, 2 \mu \mathrm{g} \mathrm{ml}^{-1}, 5 \mu \mathrm{g} \mathrm{ml}^{-1}\right)$. The concentrations were determined after a series of preexperiments. The samples were analyzed in terms of motility, viability, acrosomal status and lipid peroxidation level immediately after sperm preparation (time point $0 \mathrm{hr}$ ) and at $2 \mathrm{hrs}$ and $4 \mathrm{hrs}$ incubation at $37^{\circ} \mathrm{C}$. The experiment was repeated 4 times $(n=4)$.

The study was conducted under Good Laboratory Practice (GLP) conditions and the approval of the Research Ethical Committee of Faculty of Veterinary Medicine, 5/2013, Aristotle University.

\section{The grape extract}

The grape pomace used belongs to the species Vitis vinifera and to the variety Batiki Tyrnavou (white grapes grown in Central Greece). The raw material was dried in a shady, well-ventilated place and extracted with ethanol (96\%) at $50^{\circ} \mathrm{C}$ for $4 \mathrm{hrs}$. After filtration, the solvent was evaporated under reduced pressure, and the residue (grape pomace extract) was kept at $-20^{\circ} \mathrm{C}$ until the time of the experiment. The exact polyphenolic composition of the tested extract has been determined by Veskoukis et al. [28].

\section{Computer Assisted Sperm Analysis (CASA) for motility parameters}

A sample from each incubation tube was subjected to motion analysis. At the initial time point, $10 \mu \mathrm{l}$ from each sample were transferred onto a warmed slide and covered with a cover slip $(22 \times 22 \mathrm{~mm})$ at $37^{\circ} \mathrm{C}$. The CASA system consisted of a triocular optical phase contrast microscope (Nicon Eclipse E200; Nikon, Tokyo, 
Japan), equipped with a warming stage (Tokai, Japan) at $37^{\circ} \mathrm{C}$ and a Basler Scout CCD digital camera (Basler Vision Technologies, Ahrensburg, Germany). The camera was connected to a computer. For each treatment, two samples and 5 fields per sample taken at random were recorded and analyzed using Integrated Semen Analysis System software (ISAS MvCo, Valencia, Spain). Sampling was carried out using a $20 \times$ negative phase contrast objective. Image sequences were saved and analyzed afterwards. The standard parameter settings were as follows: 25 frames $\sec ^{-1}, 20-90 \mu \mathrm{m}^{2}$ for head area, $\mathrm{VCL}>10 \mu \mathrm{m} \mathrm{sec}^{-1}$ to classify a spermatozoon as motile. For each sample, the following characteristics of sperm motility were determined: percentages of motile ("Rapid", "Medium", "Slow"), and progressively motile spermatozoa; percentage of total motile spermatozoa, three velocity parameters ( $\mathrm{VCL}$, velocity according to the actual path; VSL, velocity according to the straight path; VAP, velocity according to the smoothed path) and the amplitude of the lateral displacement of the sperm head (ALH) [34].

\section{One-step eosin-nigrosin staining technique for viability and acrosomal status}

Additionally, a $5 \mu \mathrm{l}$ sample from the control and four different grape extract concentrations were stained with $10 \mu \mathrm{l}$ of eosin Y/nigrosin. Smears of spermatozoa in duplicates were prepared, according to this technique [35], immediately after thawing (time point $0 \mathrm{hr}$ ) and at $2 \mathrm{hrs}$ and $4 \mathrm{hrs}$ incubation at $37^{\circ} \mathrm{C}$. Forty smears of sperm were tested and 200 spermatozoa were counted from each slide. Stained smears were evaluated according to their viability and acrosomal status and classified as alive and dead spermatozoa with intact or non-intact acrosome.

\section{Measurement of lipid peroxidation}

Lipid oxidation was assessed by the TBARS (ThioBarbituric Acid Reactive Substances) assay on the basis of MDA formation [36]. MDA, the compound used as an index of lipid peroxidation, was determined by a selective third-order derivative spectrophotometric method (Shimadzu Model UV-160A), slightly modified to spermatozoa. In brief, $10^{7}$ washed spermatozoa which have been previously treated or not with different concentration of a polyphenol-rich grape pomace extract $\left(1 \mu \mathrm{g} \mathrm{ml}{ }^{-1}\right.$, $2 \mu \mathrm{g} \mathrm{ml}^{-1}, 5 \mu \mathrm{g} \mathrm{ml}^{-1}$ ) were mixed with $50 \mu \mathrm{FeSO}_{4} 7 \mathrm{H}_{2} \mathrm{O}$ $(5 \mathrm{mM})$ and $2900 \mu \mathrm{l}$ distilled water for $1 \mathrm{hr}$ and incubated for $1 \mathrm{hr}$ at $37^{\circ} \mathrm{C}$. After $2 \mathrm{hrs}$ and 4 of hrs of total incubation, the samples were mixed with $500 \mu$ trichloroacetic acid 35\% and $2000 \mu \mathrm{l}$ butylated hydroxytoluene (BHT) in hexane and were centrifuged at $2000 \mathrm{~g}$ for $1 \mathrm{~min}$. The top hexane layer was discarded and the bottom aqueous layer $(2500 \mu \mathrm{l})$ was transferred to another tube containing $1500 \mu \mathrm{l}$ thiobarbituric acid (TBA). After
$30 \mathrm{~min}$ of incubation $\left(70^{\circ} \mathrm{C}\right)$, the tubes were allowed to cool under tap water, and submitted to third-order derivative spectrophotometry. The concentration of MDA (ng per $10^{7}$ spermatozoa) was calculated on the basis of the height of the third-order derivative peak at $521.5 \mathrm{~nm}$ by referring to slope and intercept data of the computed least squares fit of a standard calibration curve prepared using 1,1,3,3-tetrahethoxypropane.

\section{Statistical analysis}

The parameters: "Rapid", "Progressive Motility", "Total motility", VCL, VSL, VAP and ALH were analyzed as repeated measurements using the LS Means Differences Tukey HSD-test $(p<0.05)$. The percentage of sperm viability was analyzed by the Chi-Square Goodness of Fit Test for a Poisson distribution $(p<0.05)$. Repeated measures ANOVA with the Bonferroni correction were used for statistical analysis of MDA formation, where the interaction between different concentration and time points was analyzed $(p<0.05)$.

\section{Competing interests}

The authors declare that they have no competing interests.

\section{Authors' contributions}

VS: CASA in the preliminary experiments with different doses of the extract and in the main experiments as well. MDA, Drafted the manuscript. IM: Participated in the design of the study, prepared the extracts, statistical analysis, writing assistance. NS: CASA parameters, pre-experiment. KA: CASA parameters, pre-experiment. ED: Viability technical assistance. IT: MDA, Helped to draft the manuscript. IZ: Viability, extract preparations. AT: Statistical Analysis. MT: Conceived the study, coordination of the study, interpretation of the data, wrote part of the manuscript. All authors read and approve the final manuscript.

\section{Author details}

${ }^{1}$ Laboratory of Physiology, School of Veterinary Medicine, Faculty of Health Science, Aristotle University of Thessaloniki, 54124 Thessaloniki, Greece.

${ }^{2}$ Laboratory of Animal Production Economics, School of Veterinary Medicine, Faculty of Health Science, Aristotle University of Thessaloniki, 54124 Thessaloniki, Greece.

Received: 17 June 2014 Accepted: 15 October 2014 Published: 3 November 2014

\section{References}

1. Vijayaraghavan S: Sperm motility: patterns and regulation. In Introduction to Mammalian Reproduction. 2nd edition. Edited by Tulsiani D. Boston, USA: Kluwer Academic Publishers; 2003:79-91.

2. Lonergan P: The application of in vitro fertilization techniques to the prediction of fertility. Reprod Domest Anim 1994, 29:12-21.

3. Kasimanickam R, Nebel RL, Peeler ID, Silvia WL, Wolf KT, McAllister AJ, Cassell BG: Breed differences in competitive indices of Holstein and Jersey bulls and their association with sperm DNA fragmentation index and plasma membrane integrity. Theriogenology 2006, 66:1307-1315.

4. Correa JR, Pace MM, Zavos PM: Relationships among frozen-thawed sperm characteristics assessed via the routine semen analysis, sperm functional tests and fertility of bulls in artificial insemination program. Theriogenology 1997, 48:721-731.

5. Farrell PB, Presicce GA, Brockett CC, Foote RH: Quantification of bull sperm characteristics measured by computer-assisted sperm analysis (CASA) and the relationship to fertility. Theriogenology 1998, 49:871-879.

6. Jones R, Mann T, Sherins P: Peroxidative breakdown of phospholipids in human spermatozoa, spermicidal properties of fatty acid peroxides and protective action of seminal plasma. Fertil Steril 1979, 3:531-537. 
7. de Lamirande E, O'Flaherty C: Sperm activation: role of reactive oxygen species and kinases. Biochim Biophys Acta 2008, 1784:106-115.

8. Zini A, Garrels K, Phang D: Antioxidant activity in the semen of fertile and infertile men. Urology 2000, 55:922-926.

9. Twigg J, Fulton N, Gomez E, Irvine DS, Aitken RJ: Analysis of the impact of intracellular reactive oxygen species generation on the structural and functional integrity of human spermatozoa: lipid peroxidation, DNA fragmentation and effectiveness of antioxidants. Hum Reprod 1998, 13:1429-1436.

10. Aitken RJ, Clarkson JS, Fishel S: Generation of reactive oxygen species, lipid peroxidation and human sperm function. Biol Reprod 1989, 41:183-197.

11. Makker K, Agarwal A, Sharma R: Oxidative stress and male infertility. Indian J Med Res 2009, 129:357-367.

12. Bilodeau JF, Blanchette $\mathrm{S}$, Gagnon C, Sirard MA: Thiols prevent $\mathrm{H}_{2} \mathrm{O}_{2}$-mediated loss of sperm motility in cryopreserved bull semen. Theriogenology 2001, 56:275-286.

13. Domínguez-Rebolledo AE, Fernández-Santos MR, Bisbal A, Ros-Santaella JL, Ramón M, Carmona M, Martínez-Pastor F, Julián Garde JJ: Improving the effect of incubation and oxidative stress on thawed spermatozoa from red deer by using different antioxidant treatments. Reprod Fertil Dev 2010, 22:856-870

14. Sapanidou V, Taitzoglou I, Tsakmakidis I, Abas Z, Zervos I, Lavrentiadou S, Tsantarliotou M: Crocin improves frozen/thawed bovine sperm motility and viability. In Proceedings of 16 th Annual Conference of European Society for Domestic Animal Reproduction, 29 August-1 September, Dublin, Ireland. Edited by Crowe MA, Beltman M. 2012:108.

15. Chidambara Murthy KN, Singh RP, Jayaprakasha GK: Antioxidant activities of grape (Vitis vinifera) pomace extracts. J Agric Food Chem 2002, 50:5909-5914

16. Soleas GJ, Diamandis EP, Goldberg DM: Wine as a biological fluid: history, production, and role in disease prevention. J Clin Lab Anal 1997, 11:287-313

17. Degáspari $\mathrm{CH}$, Waszczynskyj N: Propriedades antioxidantes de compostos fenólicos [antioxidant properties of phenolic compounds]. Visão Acad 2004, 5:33-40.

18. Stagos D, Kazantzoglou G, Theofanidou D, Kakalopoulou G, Magiatis P, Mitaku S, Kouretas D: Activity of grape extracts from Greek varieties of Vitis vinifera against mutagenicity induced by bleomycin and hydrogen peroxide in Salmonella typhimurium strain TA102. Mutat Res 2006, 609:165-175.

19. Stagos D, Spanou C, Margariti M, Stathopoulos C, Mamuris Z, Kazantzoglou $G$, Magiatis P, Kouretas D: Cytogenetic effects of grape extracts (Vitis vinifera) and polyphenols on mitomycin C-induced sister chromatid exchanges (SCEs) in human blood lymphocytes. J Agric Food Chem 2007 55:5246-5252

20. Summerfield FW, Tappel AL: Determination of malondialdehyde-DNA crosslinks by fluorescence and incorporation of tritium. Anal Biochem 1981, 111:77-82.

21. Alvarez JG, Storey BT: Spontaneous lipid peroxidation in rabbit epididymal spermatozoa: its effects on sperm motility. Biol Reprod 1982, 27:1102-1108

22. Griveau JF, Le Lannou D: Reactive oxygen species and human spermatozoa: physiology and pathology. Int J Androl 1997, 20:61-69.

23. Januskauskas A, Johannisson A, Rodriguez-Martinez H: Subtle membrane changes in cryopreserved bull semen in relation with sperm viability, chromatin structure, and field fertility. Theriogenology 2003, 60:743-758.

24. Singh $P$, Chand D, Georgie GC: Effect of vitamine $E$ on lipid peroxidation in buffalo Bubalus bubalis L. Indian J Exp Biol 1989, 27:14-16.

25. Verma A, Kanwar KC: Human sperm motility and lipid peroxidation in different ascorbic acid concentrations: an in vitro analysis. Andrologia 1998, 30:325-329.

26. Bansal AK, Bilaspuri GS: Antioxidant effect of vitamin E on motility, viability and lipid peroxidation of cattle spermatozoa under oxidative stress. Anim Sci Pap Rep 2009, 27:5-14.

27. McNiven MA, Richardson GF: Effect on quercetin on capacitation status and lipid peroxidation of stallion spermatozoa. Cell Preserv Technol 2006, 4:169-177.

28. Veskoukis AS, Kyparos A, Nikolaidis MG, Stagos D, Aligiannis N, Halabalaki M, Chronis K, Goutzourelas N, Skaltsounis L, Kouretas D: The antioxidant effects of a polyphenol-rich grape pomace extract in vitro do not correspond in vivo using exercise as an oxidant stimulus. Oxid Med Cell Longev 2012, 2012. doi:10.1155/2012/185867

29. Chen $L$, Yang $X$, Jiao $H$, Zhao B: Tea catechins protect against lead-induced ROS formation, mitochondrial dysfunction, and calcium dysregulation in PC12 cells. Chem Res Toxicol 2003, 16:1155-1161.

30. Silva EC, Cajueiro JF, Silva SV, Soares PC, Guerra MM: Effect of antioxidants resveratrol and quercetin on in vitro evaluation of frozen ram spermen. Theriogenology 2012, 77:1722-1726.

31. Lima LRP, de Oliveira TT, Nagem TJ, Pinto AS, Stringheta PC, Tinoco ALA, da Silva JF: Bixina, Norbixina e Quercetina e seus efeitos no metabolismo lipídico de coelhos [Bixin, Norbixin and Quercetin and lipid metabolism effects in rabbits]. Braz J Vet Res Anim Sci 2001, 38:196-200.

32. de Lamirande $E$, Jiang $H$, Zini A, Kodama H, Gagnon C: Reactive oxygen species and sperm physiology. Rev Reprod 1997, 2:48-54.

33. Kodama $H$, Kuribayashi $Y$, Gagnon C: Effect of sperm lipid peroxidation on fertilization. J Androl 1996, 17:151-157.

34. Mortimer D, Goel N, Shu MA: Evaluation of the Cell Soft automated semen analysis system in a routine laboratory setting. Fertil Steril 1988, 50:960-968.

35. Björndahl L, Söderlund I, Kvist U: Evaluation of the one-step eosin-nigrosin staining technique for human sperm vitality assessment. Hum Reprod 2003, 18:813-816.

36. Botsoglou NA, Fletouris DJ, Papageorgiou GE, Vassilopoulos VN, Mantis AJ, Trakatellis AG: Rapid, sensitive and specific thiobarbituric acid method for measuring lipid peroxidation in animal tissue, food, and feedstuff samples. J Agric Food Chem 1994, 42:1931-1937.

doi:10.1186/2241-5793-21-19

Cite this article as: Sapanidou et al:: Antioxidant effect of polyphenol-rich grape pomace extract on motility, viability and lipid peroxidation of thawed bovine spermatozoa. Journal of Biological Research-Thessaloniki 2014 21:19.

\section{Submit your next manuscript to BioMed Central and take full advantage of:}

- Convenient online submission

- Thorough peer review

- No space constraints or color figure charges

- Immediate publication on acceptance

- Inclusion in PubMed, CAS, Scopus and Google Scholar

- Research which is freely available for redistribution 